\title{
Association of atrial arrhythmias with thrombospondin-1 in patients with acute myocardial infarction
}

Wenkai Liao ${ }^{1+}$, Li Xu ${ }^{1 \dagger}$, Yuxia Pan ${ }^{1}$, Jie Wei ${ }^{1}$, Peijia Wang ${ }^{1}$, Xinchun Yang ${ }^{1}$, Mulei Chen ${ }^{1,2^{*}}$ and Yuanfeng Gao ${ }^{1,2^{*}}$

\begin{abstract}
Objectives: Atrial remodeling is the main developmental cause of atrial arrhythmias (AA), which may induce atrial fibrillation, atrial flutter, atrial tachycardia, and frequent premature atrial beats in acute myocardial infarction (AMI) patients. Thrombospondin-1 (TSP-1) has been shown to play an important role in inflammatory and fibrotic processes, but its role in atrial arrhythmias is not well described. The purpose of this study was to investigate the role of TSP-1 in AMl patients with atrial arrhythmias.

Methods: A total of 219 patients with AMI who underwent percutaneous coronary intervention and with no previous arrhythmias were included. TSP-1 were analyzed in plasma samples. Patients were classified into 2 groups, namely, with and without AA during the acute phase of MI. Continuous electrocardiographic monitoring was used for AA diagnosis in hospital.

Results: Twenty-four patients developed AA. Patients with AA had higher TSP-1 levels $(29.01 \pm 25.87 \mu \mathrm{g} / \mathrm{mL}$ vs $18.36 \pm 10.89 \mu \mathrm{g} / \mathrm{mL}, p<0.001)$ than those without AA. AA patients also tended to be elderly $(65.25 \pm 9.98$ years vs $57.47 \pm 10.78$ years, $p<0.001)$, had higher $\mathrm{Hs}-\mathrm{CRP}(39.74 \pm 43.50 \mathrm{mg} / \mathrm{L}$ vs $12.22 \pm 19.25 \mathrm{mg} / \mathrm{L}, p<0.001)$ and worse heart function. TSP-1 (OR 1.033; 95\% Cl 1.003-1.065, $p=0.034$ ), Hs-CRP (OR 1.023; 95\% Cl 1.006-1.041, $p=0.008$ ), age (OR 1.067; 95\% Cl 1.004-1.135, $p=0.038$ ) and LVDd (OR 1.142; 95\% Cl 1.018-1.282, $p=0.024$ ) emerged as independent risk factors for $\mathrm{AA}$ in $\mathrm{AMl}$ patients.
\end{abstract}

*Correspondence: chenmulei666@163.com; gaoyuanwind1@163.com

tWenkai Liao and Li Xu have contributed equally to this work

2 Department of Cardiology, Chaoyang Hospital, Capital Medical

University, 8th Gongtinan Rd, Chaoyang District, Beijing 100020, China

Full list of author information is available at the end of the article

(c) The Author(s) 2021. Open Access This article is licensed under a Creative Commons Attribution 4.0 International License, which permits use, sharing, adaptation, distribution and reproduction in any medium or format, as long as you give appropriate credit to the original author(s) and the source, provide a link to the Creative Commons licence, and indicate if changes were made. The images or other third party material in this article are included in the article's Creative Commons licence, unless indicated otherwise in a credit line to the material. If material is not included in the article's Creative Commons licence and your intended use is not permitted by statutory regulation or exceeds the permitted use, you will need to obtain permission directly from the copyright holder. To view a copy of this licence, visit http://creativecommons.org/licenses/by/4.0/. The Creative Commons Public Domain Dedication waiver (http://creativecommons.org/publicdomain/zero/1.0/) applies to the data made available in this article, unless otherwise stated in a credit line to the data. 
Conclusion: TSP-1 is a potential novel indicator of atrial arrhythmias during AMI.

\section{Graphic abstract:}

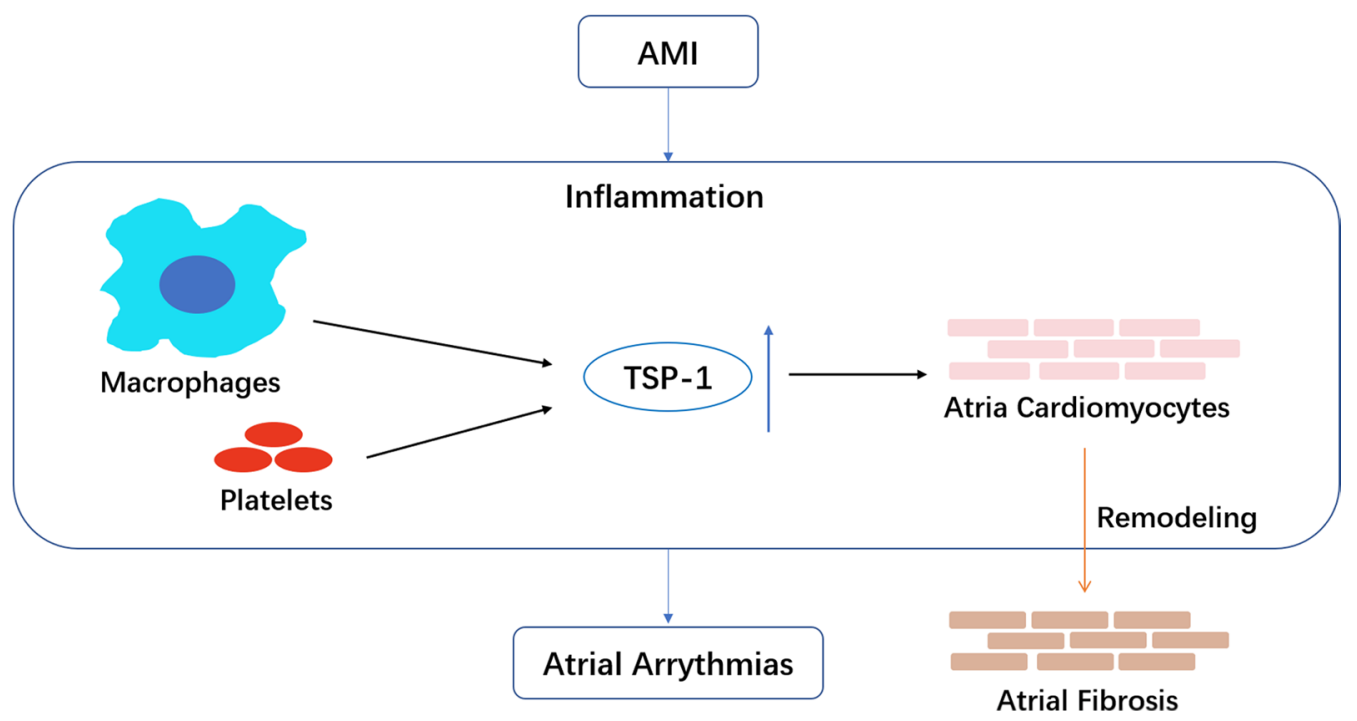

Keywords: Atrial arrhythmias, Atrial fibrillation, Atrial remodeling, Acute myocardial infarction, Thrombospondin-1

\section{Introduction}

Atrial fibrillation (AF) is one the most frequently encountered arrhythmias. AF affects $\sim 33$ million worldwide, and both its incidence and associated mortality are increasing. Atrial arrhythmias (AA) are a group of supraventricular arrhythmias including atrial flutter, atrial tachycardia, and premature atrial beats that may eventually develop into AF and therefore requires anticoagulation therapy [1]. Coronary artery disease is one of the main risk factors of $\mathrm{AF}$, along with hypertension, diabetes mellitus, obesity, and age [2].

Acute myocardial infarction (AMI) is one of the most common causes of death worldwide. It is often complicated by supraventricular arrhythmias, the most frequent of which is AF. Patients with AF in AMI have more comorbidities and are at greater risk of reinfarction, strokes, heart failure, and sudden cardiac death [3, 4]. Atrial arrhythmias (AA) like atrial flutter, atrial tachycardia, and premature atrial contractions (PACs) may also develop into $\mathrm{AF}$, increasing the risks mentioned previously [5, 6]. Currently, we only use anticoagulants for AMI patients with new-onset AF for short-term management. Other atrial arrhythmias may have been ignored, despite possibly similar inflammatory mechanisms that eventually lead to atrial remodeling.

Thrombospondins consist of a family of five atrial extracellular matrix (ECM) member proteins. Of the five, thrombospondin-1 (TSP-1) is the most well described in relation to inflammation and fibrogenesis in many diseases such as liver fibrosis, diabetes, multiple tumors and cardiovascular disorders [7]. TSP-1 is a multi-modular glycoprotein consists of an $\mathrm{N}$-terminal (NH2) domain, three properdin type-I repeats, three epidermal growth factor-like type-II repeats, a calciumbinding type-III repeats, and a C-terminal $(\mathrm{COOH})$ domain that facilitates interactions with other binding partners [8]. TSP-1 is mainly expressed by macrophages and platelets that regulates inflammatory responses through the transforming growth factor- $\beta 1$ (TGF- $\beta 1$ ) pathway $[7,9,10]$. The TGF- $\beta 1$ pathway initiates inflammation and oxidative stress signaling and is important in ECM regulation and atrial fibrotic remodeling [11]. TSP-1 also interacts with cardiac matrix metalloproteinases (MMPs), collagen I and ionized calcium $\left(\mathrm{Ca}^{2+}\right)$ [12], which are thought to be critical in atrial ECM metabolism [13, 14]. We summarized a figure of TSP-1 binding partners possibly related with atrial ECM remodeling (Fig. 1). AMI acts like a trigger event of an inflammatory response that may induce an increase in TSP-1 and atrial remodeling, causing all kinds of AA, and eventually, AF.

The aim of our study was to compare TSP-1 levels in AMI patients with and without AA as a biomarker for atrial remodeling. 


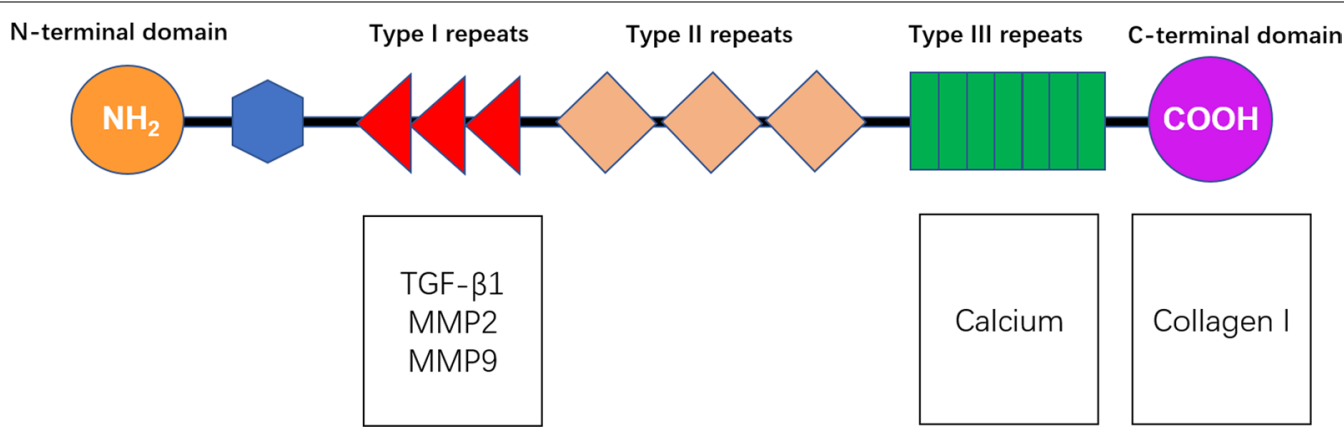

Fig. 1 TSP-1 subunit structures and binding partners that regulate atrial ECM

\section{Materials and methods \\ Study population}

This study was approved by the Medical Ethics Committees of Beijing Chaoyang Hospital. All patients at the coronary care unit (CCU), Cardiovascular Department, Beijing Chaoyang Hospital who underwent percutaneous coronary intervention (PCI) from 2019 to 2020 were enrolled. A total of 219 patients with AMI and no previous arrhythmias were included. All patients included in this study signed a written consent form. Atrial arrhythmias were defined as the presentation of any kind of atrial electrical abnormalities, including atrial fibrillation, atrial flutter, atrial tachycardia, and premature atrial beats ( $>200$ beats/day) [15]. Continuous electrocardiographic monitoring (Philips, Eindhoven, Netherlands) was performed to record atrial arrhythmias.

\section{Laboratory methods}

Fasting blood samples were drawn between 6 and 7 a.m. on day 2 after admission. Plasma for determining TSP-1 levels was prepared by centrifugation within $1 \mathrm{~h}$ at $-12{ }^{\circ} \mathrm{C}$ and $2500 \mathrm{~g}$ for $30 \mathrm{~min}$. TSP- 1 concentrations were measured by ELISA (Human Thrombospondin-1 ELISA Kit, KE1254, ImmunoWay, Plano, TX, USA). Blood samples for other biochemical characteristics were drawn at the same time and analyzed in a center laboratory of Beijing Chaoyang Hospital.

\section{Echocardiography}

All patients underwent routine transthoracic echocardiography (GE Healthcare Life Sciences, Connecticut, USA) within 3 days after admission. Standard echocardiographic parameters measured included left ventricular end-systolic diameter (LVSd), left ventricular end-diastolic diameter (LVDd), and left atrial anteroposterior diameter (LAAPd). The left ventricle ejection fraction (LVEF) was calculated from apical 2- and 4-chamber views using the Simpson's biplane method [16].

\section{Statistical methods}

Continuous data were presented as means $\pm S D$, and non-continuous variables were expressed as frequencies. We compared continuous variations using an independent $t$-test and categorical variables using the Pearson $\chi^{2}$ test. Univariable analysis was used to identify the risk factors for AA. The potential association between TSP-1 and AA in AMI patients was identified by multivariate logistic regression analysis. SPSS v22.0 (SPSS Inc., Chicago, IL, USA) was used for statistical calculations and illustrations. All tests were two-sided, and $p<0.05$ was considered statistically significant.

\section{Results}

\section{Baseline characteristics of AMI patients}

The subjects were composed of 186 males (84.9\%) and 33 females (15.1\%). The youngest patient was 24 years old, whereas the oldest was 79 (mean age $58.32 \pm 10.83$ years). Of the 219 patients assessed, 24 (11.0\%) developed AA, including 16 patients (7.3\%) with AF, 1 patient $(0.5 \%)$ with atrial tachycardia, and 7 patients (3.2\%) with frequent PACs $>200 / 24 \mathrm{~h}$. The type of AF that patients had were all paroxysmal AF and terminated either naturally or with the administration of amiodarone. No patients developed ventricular arrhythmias during the monitoring period. The clinical and biochemical characteristics of AA and non-AA groups are summarized in Table 1.

Patients with AA tended to be older compared with patients without AA $(65.25 \pm 9.98$ vs $57.47 \pm 10.78$ years, $p=0.001$ ). No significant differences were observed between the two groups regarding gender, heart rate, and systolic blood pressure (SBP) on admission, AMI type, previous hypertension history, diabetes mellitus, 
Table 1 Baseline characteristics

\begin{tabular}{|c|c|c|c|}
\hline & $\begin{array}{l}A A \\
(n=24)\end{array}$ & $\begin{array}{l}\text { No-AA } \\
(n=195)\end{array}$ & AA vs. no-AA, $p$ \\
\hline \multicolumn{4}{|l|}{ Clinical characteristics } \\
\hline Age, years & $65.25 \pm 9.98$ & $57.47 \pm 10.78$ & 0.001 \\
\hline Gender, males & $19(79.17)$ & $167(85.64)$ & 0.403 \\
\hline Weight, kg & $69.52 \pm 7.64$ & $75.31 \pm 9.95$ & 0.007 \\
\hline Heart rate on admission, (per min) & $74.79 \pm 12.33$ & $77.78 \pm 12.00$ & 0.252 \\
\hline SBP on admission, $\mathrm{mmHg}$ & $122.75 \pm 25.20$ & $127.75 \pm 19.63$ & 0.256 \\
\hline \multicolumn{4}{|l|}{ AMl type } \\
\hline STEMI & $14(58.33)$ & $126(64.62)$ & 0.545 \\
\hline NSTEMI & $10(41.67)$ & $69(35.38)$ & 0.545 \\
\hline \multicolumn{4}{|l|}{ Killip classification } \\
\hline | & $12(50)$ & $103(52.82)$ & 0.794 \\
\hline$\|$ & $7(29.17)$ & $85(43.59)$ & 0.177 \\
\hline III & $3(12.5)$ & $5(2.56)$ & 0.014 \\
\hline IV & $2(8.33)$ & $2(1.03)$ & 0.012 \\
\hline Patients with history of hypertension & $13(54.17)$ & $102(52.31)$ & 0.863 \\
\hline Patients with history of diabetes mellitus & $9(37.5)$ & $63(32.31)$ & 0.609 \\
\hline Patients with history of hyperlipidemia & $44(22.56)$ & $5(20.83)$ & 0.848 \\
\hline Patients with history of previous myocardial infarction & $6(25)$ & $30(15.38)$ & 0.230 \\
\hline Patients with history of stroke & $3(12.5)$ & $22(11.28)$ & 0.859 \\
\hline Family members with premature cardiovascular disease & $12(50)$ & $68(34.87)$ & 0.084 \\
\hline Use of $\beta$-blockers & $11(45.83)$ & $135(69.23)$ & 0.022 \\
\hline Use of ACEI/ARB & $4(16.67)$ & $82(42.05)$ & 0.016 \\
\hline \multicolumn{4}{|l|}{ Echocardiography } \\
\hline LAAPd, mm & $38.46 \pm 5.12$ & $37.31 \pm 21.94$ & 0.799 \\
\hline LVDd, mm & $50.29 \pm 4.15$ & $47.83 \pm 4.08$ & 0.006 \\
\hline LVSd, mm & $36.04 \pm 5.95$ & $32.13 \pm 5.48$ & 0.001 \\
\hline LVEF, \% & $50.83 \pm 12.62$ & $59.16 \pm 10.57$ & $<0.001$ \\
\hline \multicolumn{4}{|l|}{ Biochemical characteristics } \\
\hline Hemoglobin, g/L & $133.33 \pm 16.41$ & $140.76 \pm 24.02$ & 0.143 \\
\hline Total cholesterol, mmol/L & $4.02 \pm 0.94$ & $4.59 \pm 1.13$ & 0.018 \\
\hline $\mathrm{HDL}, \mathrm{mmol} / \mathrm{L}$ & $0.97 \pm 0.29$ & $0.95 \pm 0.22$ & 0.615 \\
\hline $\mathrm{LDL}, \mathrm{mmol} / \mathrm{L}$ & $2.50 \pm 1.09$ & $3.03 \pm 0.99$ & 0.016 \\
\hline cTnl, ng/mL & $81.41 \pm 115.33$ & $92.10 \pm 121.38$ & 0.683 \\
\hline BNP, pg/mL & $1177.6 \pm 1269.00$ & $218.34 \pm 348.10$ & $<0.001$ \\
\hline Creatinine, $\mu \mathrm{mol} / \mathrm{L}$ & $112.45 \pm 117.84$ & $70.13 \pm 23.31$ & $<0.001$ \\
\hline $\mathrm{Hs}-\mathrm{CRP}, \mathrm{mg} / \mathrm{L}$ & $39.74 \pm 43.50$ & $12.22 \pm 19.25$ & $<0.001$ \\
\hline $\mathrm{ESR}, \mathrm{mm} / \mathrm{h}$ & $15.29 \pm 14.98$ & $16.72 \pm 59.95$ & 0.914 \\
\hline $\mathrm{TSP}-1, \mu \mathrm{g} / \mathrm{mL}$ & $29.01 \pm 25.87$ & $18.36 \pm 10.89$ & $<0.001$ \\
\hline
\end{tabular}

Data are presented as mean $\pm \mathrm{SD}, \mathrm{n}(\%)$

AA, atrial arrhythmias; SBP, systolic blood pressure; AMI, acute myocardial infarction; STEMI, ST-elevation myocardial infarction; NSTEMI, non-STEMI; ACEI, Angiotensinconverting enzyme inhibitors; ARB, Angiotensin II type I receptor blockers; LVEF, left ventricle ejection fraction; LVDd, left ventricle end-diastolic diameter; LVSd, left ventricle end-systolic diameter; LAAPd, left atrium anterior-posterior diameter; HDL, high-density lipoprotein LDL, low-density lipoprotein; cTnl, cardiac troponin I; BNP, brain natriuretic peptide; Hs-CRP, high sensitivity-C reactive protein; ESR, erythrocyte sedimentation rate; TSP-1, thrombospondin-1

hyperlipidemia, myocardial infarction, stroke, and family history of coronary heart disease $(p>0.05)$.

Data showed worse heart functions in patients with AA. Patients with AA had higher Killip levels (Killip III: $12.5 \%$ vs $2.56 \%, p=0.014$, Killip IV: $8.33 \%$ vs $1.03 \%$, $p=0.012$ ), higher brain natriuretic peptide (BNP) levels $(1177.67 \pm 1269.00 \mathrm{pg} / \mathrm{mL}$ vs $218.34 \pm 348.10 \mathrm{pg} /$ $\mathrm{mL}, \quad p<0.001)$, larger LVDd $(50.29 \pm 4.15 \mathrm{~mm}$ vs $47.83 \pm 4.08 \mathrm{~mm}, p=0.006)$ and LVSd $(36.04 \pm 5.95 \mathrm{~mm}$ vs $32.13 \pm 5.48 \mathrm{~mm}, p=0.001)$, and lower LVEF 
$(50.83 \% \pm 12.62 \%$ vs $59.16 \% \pm 10.57 \%, p<0.001)$. On the other hand, no significant differences were observed in the LAAPd $(p>0.05)$ since all patients had no previous arrhythmias. Patients with AA also used fewer $\beta$-blockers $(45.83 \%$ vs $69.23 \%, p=0.022)$ and angiotensin-converting enzyme inhibitors (ACEI)/angiotensin II type I receptor blockers (ARBs) $(16.67 \%$ vs $42.05 \%$, $p=0.016)$ probably because of worse acute cardiac conditions.

Patients with AA also had lower total cholesterol $(4.02 \pm 0.94 \mathrm{mmol} / \mathrm{L}$ vs $4.59 \pm 1.13 \mathrm{mmol} / \mathrm{L}, p=0.018)$, lower low-density lipoprotein (LDL, $2.50 \pm 1.09 \mathrm{mmol} / \mathrm{L}$ vs $3.03 \pm 0.99 \mathrm{mmol} / \mathrm{L}, p=0.016)$, and lower body weights $(69.52 \pm 7.64 \mathrm{~kg}$ vs $75.31 \pm 9.95 \mathrm{~kg}, p=0.007)$. No significant difference in high-density lipoprotein (HDL) was observed between the groups $(p>0.05)$.

Patients with AA had higher creatinine levels $(112.45 \pm 117.84 \mu \mathrm{mol} / \mathrm{L} \quad$ vs $70.13 \pm 23.31 \mu \mathrm{mol} / \mathrm{L}$, $p<0.001)$ than patients without AA, whereas no differences were observed in hemoglobin and cardiac troponin I (cTnI) levels $(p>0.05)$.

The plasma TSP-1 levels $(29.01 \pm 25.87 \mu \mathrm{g} / \mathrm{mL}$ vs $18.36 \pm 10.89 \mu \mathrm{g} / \mathrm{mL}, p<0.001)$ were significantly higher in patients with AA than patients without. High sensitivity-C reactive protein (Hs-CRP, $39.74 \pm 43.50 \mathrm{mg} / \mathrm{L}$ vs $12.22 \pm 19.25 \mathrm{mg} / \mathrm{L}, p<0.001)$ was also higher in AA patients. No differences in erythrocyte sedimentation rate (ESR) levels were observed between the groups $(p>0.05)$.

\section{Multivariate logistic regression reveals TSP-1 as an independent risk factor for newly onset atrial arrhythmias}

Univariate analysis for AA risk assessment was performed for the significantly different variables mentioned above. A multivariate logistic regression model was built to find risk factors for AA. As shown in Table 2, TSP-1 (OR 1.042; 95\% CI 1.013-1.072, $p=0.004$ ), age (OR 1.091; 95\% CI 1.033-1.153, $p=0.002$ ), Hs-CRP (OR 1.027; 95\% CI 1.012-1.043, $p=0.001$ ), and LVDd (OR 1.142; 95\% CI $1.018-1.282, p=0.024)$ emerged as independent risk factors for AA after adjusting for other potential risk factors.

\section{Discussion}

AF is becoming more and more prevalent in clinical settings, and yet, the mechanisms are still poorly understood. However, the substrates of AF occurrence are increasingly being examined, improving current knowledge beyond the clinical classification of AF. Aguilar et al. [17] found a model demonstrating that the occurrence of AF is determined by the AF substrate, which in turn is governed by unmodifiable conditions, like genetic influences, aging, and modifiable conditions, like cardiovascular disease and obesity. AF is also determined by the transient substrate, which is produced by a triggering event (like cardiac surgery or an acute illness), inducing a transient increase in inflammation signaling, oxidative stress, and hemodynamic changes. The gradual, time-related progression of the AF substrate eventually reaches the AF threshold, and spontaneous AF occurs. Cumulative trials have also proved atrial arrhythmias like premature atrial contractions, atrial flutter, and atrial tachycardia may convert into AF and thus needs anticoagulation treatment $[1,15,18,19]$. We hypothesized that the triggering event (AMI in our study) may trigger all kinds of AA with possibly homologous mechanisms. In our trials, the plasma TSP-1 levels $(29.01 \pm 25.87 \mu \mathrm{g} /$ $\mathrm{mL}$ vs $18.36 \pm 10.89 \mu \mathrm{g} / \mathrm{mL}, p<0.001)$ were significantly higher in patients with AA than patients without, which indicates patients with post-AMI AA, other than AF, may also need evaluation for potential risks of stroke and heart failure.

Table 2 Factors independently associated with newly onset AA in AMI patients

\begin{tabular}{|c|c|c|c|c|c|c|}
\hline & \multicolumn{3}{|c|}{ Univariate } & \multicolumn{3}{|c|}{ Multivariate } \\
\hline & OR & $95 \% \mathrm{Cl}$ & $p$ value & $\overline{O R}$ & $95 \% \mathrm{Cl}$ & $p$ value \\
\hline TSP-1 & 1.041 & $1.013-1.069$ & 0.003 & 1.042 & $1.013-1.072$ & 0.004 \\
\hline Age & 1.083 & $1.031-1.132$ & 0.001 & 1.091 & $1.033-1.153$ & 0.002 \\
\hline $\mathrm{Hs}-\mathrm{CRP}$ & 1.029 & $1.016-1.042$ & 0.000 & 1.027 & $1.012-1.043$ & 0.001 \\
\hline LVDd & 1.150 & $1.038-1.273$ & 0.007 & 1.142 & $1.018-1.282$ & 0.024 \\
\hline LVEF & 0.937 & $0.902-0.927$ & 0.001 & & & \\
\hline BNP & 1.001 & $1.000-1.002$ & 0.001 & & & \\
\hline Killip level & 1.734 & $0.979-3.072$ & 0.059 & & & \\
\hline Creatinine & 1.014 & $1.003-1.024$ & 0.008 & & & \\
\hline Weight & 0.931 & $0.885-0.980$ & 0.006 & & & \\
\hline
\end{tabular}

TSP-1, Thrombospondin-1; OR, odds ratio; $\mathrm{Cl}$, confidence interval; $\mathrm{Hs}$-CRP, high sensitivity-C reactive protein; BNP, brain natriuretic peptide; LVEF, left ventricle ejection fraction; LVDd, left ventricle end-diastolic diameter 
TSP-1 is mainly expressed by macrophages and platelets that may regulate atrial remodeling through multiple pathways, mainly through the TSP-1/TGF- $\beta 1$ pathway. TSP-1 may bind and activate latent TGF- $\beta$, promoting the inflammatory response via recruitment of inflammatory cells and increase myofibroblast differentiation. Besides the TGF- $\beta 1$ pathway, the C-terminal domain of TSP-1 may bind to collagen I directly, regulating fibroblast activities [20]. TSP-1 may also interact with MMP-2 and MMP-9, possibly inhibiting their activity and regulating collagen homeostasis [21]. Procter et al. [22] also found platelet hyperaggregability, induced by the release of TSP-1 from platelet $\alpha$-granules, may diminish nitric oxide signaling, thus promoting inflammation. Recently, Zhou et al. [23] reported that microRNA-221 could inhibit latent TGF- $\beta 1$ activation by targeting TSP- 1 to attenuate cardiac fibrosis, which could be a possible upstream treatment of AA.

Previous studies showed conflicting evidence of TSP-1 during AMI. One study reported that TSP-1 could have a protective role in preventing the expansion of healing myocardial infarcts [24], but another stated that low TSP-1 could be associated with major adverse cardiac events in ST-elevation myocardial infarction [25]. Befekadu et al. [26] found TSP-1 rapidly declined after P CI even significantly lower than in healthy individuals. TSP-1 could probably be unrelated to infarct size of heart. In our study, all patients had undergone PCI before blood sample analyses for TSP-1. Our results also showed no correlation between cTnI and TSP-1 $(p=0.211)$.

As a traditional marker of inflammation in AA, Hs-CRP levels have been found significantly higher in patients with AA [27]. However, the substantial mechanism involving Hs-CRP remains unclear. In our study, significant differences in Hs-CRP levels were found between the two groups. We also found that AMI patients with AA were mostly elderly and had cardiac functions and greater levels of creatinine, which were consistent with previous studies [28-30]. Patients with AA in our study needed lesser ACEI/ARBs and $\beta$-blockers probably due to limitations of renal and heart functions. We also found lower LDL, which was consistent with a previous study [31], as well as total cholesterol and body weight, in AA patients. Of all the factors that were significantly different between the AA and non-AA groups, only TSP-1, Hs-CRP, and age were found statistically significant by multivariate logistic regression analysis in our predictive model, which suggests a possibly stronger relationship between the incidence of AA and inflammation as well asage.

In our study, TSP-1 worked as a potential novel indicator of atrial arrhythmias during AMI. AMI patients with higher serum TSP-1 levels were more likely to develop AA than the other patients. TSP-1 could also be indicators for AA prediction without AMI. Further studies are needed to explore the relationships between TSP-1 and AA prediction, severity and even relapse after treatment. Lastly, TSP-1 could be possible treatment target for atrial arrythmias.

\section{Conclusion}

In summary, TSP-1 is an important component of the inflammatory response that contributes to atrial remodeling. It may serve as a potential indicator of atrial arrhythmias post AMI, and thus indicating the need for anticoagulation and possible upstream treatments.

\section{Limitations}

Our study had several limitations. Firstly, the sample size of the AA group was relatively small. However, as a hypothesis-generating study, the present study offers valuable insights towards the clarification of the relationship between TSP-1 and new-onset AA post AMI, as well as on the possible substrate of post-AMI AA patients (with preexisting atrial remodeling). Secondly, the prevalence of AA and the long-term outcomes still need further investigation to elucidate the potential use of TSP-1 in risk stratification.

\section{Acknowledgements \\ Not applicable.}

\section{Authors' contributions}

M. C., Y. G. and L. X. contributed to the conception and design of the work. W.L. and Y. G. drafted the manuscript. Y. P. and J. W. contributed to the data collection for the work. P.W. contributed to the data analysis and interpretation for the work. L. X., M. C. and X.Y. critically revised the manuscript. All authors critically reviewed the manuscript and gave final approval and agree to be accountable for all aspects of work ensuring integrity and accuracy. All authors read and approved the final manuscript.

\section{Funding}

This work was supported by the National Natural Science Foundation of China (81700295) and open funding for Key Laboratory of Medical Engineering in Cardiovascular Disease Research, Ministry of Education (2020XXG-KFKT-02).

\section{Availability of data and materials}

The datasets generated and/or analyzed during the current study are not publicly available due to the restrictions of human genetics data policy of Beijing Chaoyang Hospital Ethics Committee, but are available from the corresponding author on reasonable request.

\section{Declarations}

\section{Ethics approval and consent to participate}

The study protocol was approved by the ethics committee of Beijing Chaoyang Hospital, Capital Medical University and performed in accordance with the ethical standers laid down in the 1964 Declaration of Helsinki and its later amendments. Written informed consents were obtained from all participants.

Consent for publication

Not applicable.

Competing interests

The authors declare that they have no competing interests. 


\section{Author details}

${ }^{1}$ Heart Center and Beijing Key Laboratory of Hypertension, Beijing Chaoyang Hospital, Capital Medical University, Beijing 100020, China. ${ }^{2}$ Department of Cardiology, Chaoyang Hospital, Capital Medical University, 8th Gongtinan Rd, Chaoyang District, Beijing 100020, China.

Received: 12 May 2021 Accepted: 14 October 2021 Published online: 20 October 2021

\section{References}

1. Larsen BS, Kumarathurai P, Falkenberg J, Nielsen OW, Sajadieh A. Excessive atrial ectopy and short atrial runs increase the risk of stroke beyond incident atrial fibrillation. J Am Coll Cardiol. 2015;66(3):232-41.

2. Chung MK, Refaat M, Shen WK, Kutyifa V, Cha YM, Di Biase L, Baranchuk A, Lampert R, Natale A, Fisher J, et al. Atrial fibrillation: JACC council perspectives. J Am Coll Cardiol. 2020;75(14):1689-713.

3. Jabre P, Roger VL, Murad MH, Chamberlain AM, Prokop L, Adnet F, Jouven X. Mortality associated with atrial fibrillation in patients with myocardial infarction: a systematic review and meta-analysis. Circulation. 2011;123(15):1587-93.

4. Ibanez B, James S, Agewall S, Antunes MJ, Bucciarelli-Ducci C, Bueno H, Caforio ALP, Crea F, Goudevenos JA, Halvorsen S, et al. 2017 ESC Guidelines for the management of acute myocardial infarction in patients presenting with ST-segment elevation. Rev Esp Cardiol (Engl Ed). 2017;70(12):1082.

5. Waldo AL, Feld GK. Inter-relationships of atrial fibrillation and atrial flutter mechanisms and clinical implications. J Am Coll Cardiol. 2008;51(8):779-86.

6. Ozcan C, Battaglia E, Young R, Suzuki G. LKB1 knockout mouse develops spontaneous atrial fibrillation and provides mechanistic insights into human disease process. J Am Heart Assoc. 2015:4(3):e001733.

7. Murphy-Ullrich JE, Suto MJ. Thrombospondin-1 regulation of latent TGF- $\beta$ activation: a therapeutic target for fibrotic disease. Matrix Biol. 2018;68-69:28-43.

8. Adams JC. Thrombospondins: multifunctional regulators of cell interactions. Annu Rev Cell Dev Biol. 2001;17:25-51.

9. Stenina-Adognravi O. Invoking the power of thrombospondins: regulation of thrombospondins expression. Matrix Biol. 2014;37:69-82.

10. Lopez-Dee Z, Pidcock K, Gutierrez LS. Thrombospondin-1: multiple paths to inflammation. Mediators Inflamm. 2011:2011:296069.

11. Scott $L$ Jr, Li N, Dobrev D. Role of inflammatory signaling in atrial fibrillation. Int J Cardiol. 2019;287:195-200.

12. Kale A, Rogers NM, Ghimire K. Thrombospondin-1 CD47 signaling: from mechanisms to medicine. Int J Mol Sci. 2021:22(8):4062.

13. Ravassa S, Ballesteros G, Lopez B, Ramos P, Bragard J, Gonzalez A, Moreno MU, Querejeta R, Vives E, Garcia-Bolao I, et al. Combination of circulating type I collagen-related biomarkers is associated with atrial fibrillation. J Am Coll Cardiol. 2019;73(12):1398-410.

14. Fong SPT, Agrawal S, Gong M, Zhao J. Modulated calcium homeostasis and release events under atrial fibrillation and its risk factors: a metaanalysis. Front Cardiovasc Med. 2021;8:662914.

15. Huang BT, Huang FY, Peng Y, Liao YB, Chen F, Xia TL, Pu XB, Chen M. Relation of premature atrial complexes with stroke and death: systematic review and meta-analysis. Clin Cardiol. 2017;40(11):962-9.

16. Lang RM, Badano LP, Mor-Avi V, Afilalo J, Armstrong A, Ernande L, Flachskampf FA, Foster E, Goldstein SA, Kuznetsova T, et al. Recommendations for cardiac chamber quantification by echocardiography in adults: an update from the American Society of Echocardiography and the
European Association of Cardiovascular Imaging. Eur Heart J Cardiovasc Imaging. 2015;16(3):233-70.

17. Aguilar M, Heijman J, Dobrev D, Nattel S. One ring to rule them all: continuous monitoring of patients with secondary atrial fibrillation points to a unifying underlying mechanism. Can J Cardiol. 2021;37:686-9.

18. Manolis AS. Contemporary diagnosis and management of atrial flutter: a continuum of atrial fibrillation and vice versa? Cardiol Rev. 2017;25(6):289-97.

19. Binici Z, Intzilakis T, Nielsen OW, Kober L, Sajadieh A. Excessive supraventricular ectopic activity and increased risk of atrial fibrillation and stroke. Circulation. 2010;121(17):1904-11.

20. Rosini S, Pugh N, Bonna AM, Hulmes DJS, Farndale RW, Adams JC. Thrombospondin-1 promotes matrix homeostasis by interacting with collagen and lysyl oxidase precursors and collagen cross-linking sites. Sci Signal. 2018;11(532):eaar2566.

21. Bein K, Simons M. Thrombospondin type 1 repeats interact with matrix metalloproteinase 2. Regulation of metalloproteinase activity. J Biol Chem. 2000;275(41):32167-73.

22. Procter NE, Ball J, Ngo DT, Chirkov YY, Isenberg JS, Hylek EM, Stewart S, Horowitz JD. Platelet hyperaggregability in patients with atrial fibrillation. Evidence of a background proinflammatory milieu. Herz. 2016;41(1):57-62.

23. Zhou Y, Ng DYE, Richards AM, Wang P. microRNA-221 inhibits latent TGF-beta1 activation through targeting thrombospondin-1 to attenuate kidney failure-induced cardiac fibrosis. Mol Ther Nucleic Acids. 2020;22:803-14.

24. Frangogiannis NG, Ren G, Dewald O, Zymek P, Haudek S, Koerting A, Winkelmann K, Michael LH, Lawler J, Entman ML. Critical role of endogenous thrombospondin-1 in preventing expansion of healing myocardial infarcts. Circulation. 2005;111(22):2935-42.

25. Kaiser R, Grotemeyer K, Kalsch T, Graber S, Wilkens H, Elmas E. Decreased TSP-1 following percutaneous coronary intervention is associated with major adverse cardiac events in ST-elevation myocardial infarction. Clin Hemorheol Microcirc. 2013;54(1):59-73.

26. Befekadu R, Christiansen K, Larsson A, Grenegard M. Increased plasma cathepsin S and trombospondin-1 in patients with acute ST-segment elevation myocardial infarction. Cardiol J. 2019;26(4):385-93.

27. Min-Tsun L, Chun-Kai C, Ting-Tse L, Li-Ying C, Hung-Wen T, Yen-Bin L. High-sensitivity C-reactive protein is a predictor of subsequent atrial high-rate episodes in patients with pacemakers and preserved ejection fraction. J Clin Med. 2020;9(11):3677.

28. Schnabel RB, Yin X, Gona P, Larson MG, Beiser AS, McManus DD, NewtonCheh C, Lubitz SA, Magnani JW, Ellinor PT, et al. 50 year trends in atrial fibrillation prevalence, incidence, risk factors, and mortality in the Framingham Heart Study: a cohort study. Lancet. 2015;386(9989):154-62.

29. Wang TJ, Larson MG, Levy D, Vasan RS, Leip EP, Wolf PA, D'Agostino RB, Murabito JM, Kannel WB, Benjamin EJ. Temporal relations of atrial fibrillation and congestive heart failure and their joint influence on mortality: the Framingham Heart Study. Circulation. 2003;107(23):2920-5.

30. Odutayo A, Wong CX, Hsiao AJ, Hopewell S, Altman DG, Emdin CA. Atrial fibrillation and risks of cardiovascular disease, renal disease, and death: systematic review and meta-analysis. BMJ. 2016;354:i4482.

31. Harrison SL, Lane DA, Banach M, Mastej M, Kasperczyk S, Jozwiak JJ, Lip GYH, Investigators L. Lipid levels, atrial fibrillation and the impact of age: results from the LIPIDOGRAM2015 study. Atherosclerosis. 2020;312:16-22.

\section{Publisher's Note}

Springer Nature remains neutral with regard to jurisdictional claims in published maps and institutional affiliations. 